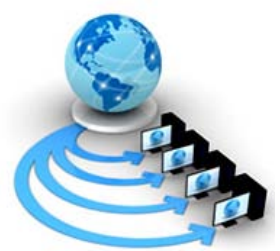

Volume 8, No. 7, July - August 2017

International Journal of Advanced Research in Computer Science

RESEARCH PAPER

Available Online at www.ijarcs.info

\title{
HYPERSPECTRAL ANALYSIS OF SOIL TOTAL NITROGEN USING ASD FILEDSPEC 4
}

\author{
Miss. Ashwini Dilip Padmanabhi \\ P.G.Student \\ Department of Computer Scinence and Technology, \\ Dr.Babasaheb Ambedkar Marathwada Univesity, \\ Aurangabad
}

\author{
Miss. Saima Ansari \\ P.G.Student \\ Department of Computer Scinence and Technology, \\ Dr.Babasaheb Ambedkar Marathwada Univesity, \\ Aurangabad
}

\author{
Dr. R. R. Deshmukh \\ Professor and HOD \\ Department of Computer Scinence and Technology, \\ Dr.Babasaheb Ambedkar Marathwada Univesity, Aurangabad
}

\begin{abstract}
The objective of this paper is to find the soil nitrogen from the agricultural soil . Measurement of total nitrogen content is necessary to improve the crop productivity. The 30 soil samples(10 scans of each sample i.e. 300 spectral signatures) of the farming land in Aurangabad and Jalna region were collected. Database creation is done using Analytical Spectral Device (ASD) Field-Spec 4 Spectroradiometer with 350$2500 \mathrm{~nm}$ wavelength band. The visible near infrared(Vis-NIR) band is used for this experiment as Vis-NIR reflectance spectroscopy require less effort and it is fast technology to find out the soil nitrogen content. Partial Least Square Regression (PLSR) technique is implemented for feature extraction of soil spectral signature. It reduces the noise and detects the unknown samples which are not represented by calibration model. It is concluded that, the statistical result $\mathrm{R}^{2}$ 0.92(p<0.01) at $403 \mathrm{~nm}, 470 \mathrm{~nm}, 687 \mathrm{~nm}, 846 \mathrm{~nm}, 1702 \mathrm{~nm}, 1870 \mathrm{~nm}$, 2052nm bands sensitive to soil nitrogen. It produces the lower prediction error RMSEV (root mean square error of validation) $=0.004$ and RMSEC (root mean square error of calibration) $=0.0039$.
\end{abstract}

Keywords : ASD Fieldspec-4 ,PLSR ,Spectral signature, Spectroradiometer, Visible near infrared (Vis-NIR).

\section{INTRODUCTION}

Soil, water and air these are the natural things which are present on or surrounding of the earth. So the soil is one of the natural things present on the earth and it is combination of gases, liquids, minerals, countless organisms and organic matter[1]. Soil is just a thin layer of surface which is made up of unconsolidated material. The interconnected ecosystem which influences every landscape has these surficial components as vital components. A soil analysis is a process by which elements such as $\mathrm{P}, \mathrm{K}, \mathrm{Ca}, \mathrm{Mg}, \mathrm{Na}, \mathrm{S}$, $\mathrm{Mn}, \mathrm{Cu}$ and $\mathrm{Zn}$ are chemically extracted from the soil and measured for their "plant available" content within the soil sample. Macro-nutrient content six nutrients, which mostly utilized in large amount. From these macronutrient nitrogen, phosphorus and potassium are critical macronutrient also known as deficient fertilizer . Nitrogen is one of the most important elements in farmland soil and it is also available in fertilizers [2]. Soil nitrite nitrogen is nonvolatility source of nitrogen for crop and it can be directly absorbed by the plant [3].For evaluating the soil quality the soil total nitrogen is one of the most important indicator. Laboratory analysis method is a traditional method to determine the soil total nitrogen content, but this method is very expensive and time consuming. So there is need to explore the accurate method which is fast and cheap also, for monitoring the soil total nitrogen content [4]. The ASD field spec 4 is one of the tool which is used to analyze the soil total nitrogen. We are using Vis-NIR band for calculating the soil total nitrogen. Vis-NIR is a reflectance Spectroscopy used to predict the soil properties. This method is rapid, it requires minimal soil preparation, it is cost effective and it has no hazardous to environment [5]. We are using the partial list square technique (PLSR) to predict the soil total nitrogen content. PLSR has ability to treat very large data matrices i.e. the data which is typically employed with hyperspectral reflectance data. Hence we can apply PLSR technique on spectral data to predict the soil total nitrogen.

\section{LITERATURE SURVEY}

Lixin Lin, et. al [6], were used the LCMCS Method(local correlation maximization-complementary superiority method) to establish TN prediction models. They consider the relationship between spectral reflectance (measured by an ASD FieldSpec 3 Spectroradiometer) and TN based on spectral reflectance curves of soil samples collected from subsided land. Authors states that the LCMCS method has great potential to monitor TN in subsided lands.

Sneha J. Bansod et. al [7] ,uses Near Infrared Spectroscopy to measure soil nitrogen NIRS is the is the rapid, nondestructive analytical technique which allows the simultaneous estimation of standard soil characteristics and does not require the use of chemicals.

$\mathrm{X} \mathrm{M}$ Shu, et.al [8], According to author Successive projections algorithm (SPA) is an effective technique for selecting informative variables and its application potential 
in estimating soil contents using visible/near-infrared reflectance (Vis/NIR) spectroscopy have not been explored. Ramdas D. Gore ,et.al [9],used a technique for classification of soil spectral signature known as Linear Discriminant Analysis(LDA) .This technique classifies the chemical properties of soil spectral signature.

LIU Xiang , et.al [10], authors uses visible near infrared spectra (vis-NIR) for mapping soil available nitrogen.

Snehal N. Kulkarni et.al [11],they use reflectance spectroscopy to determine the spectral signature of agricultural soil.

Xiaoting Peng, et. al [12],according to the author the combination of SPA and SVMR is reliable to estimate the soil organic content and also help to find the soil nitrogen .for that they use VIS/NIR of different soil types.

Rahul B. Kharat, et.al [13], found the nitrogen from the leaf of tomato plant. For that they use vegetation indices. These vegetation indices are crop reflectance indices collected from ASD field spec 4.

\section{MATERIALS AND METHODS}

\subsection{Study Area}

We have selected Aurangabad region (19 $53^{\prime} \mathrm{N}$ and $75^{\circ}$ 23' E) and Jalna region (19.8297' $\mathrm{N}$ and 75.8800 'E) which are located in Maharashtra as our study area .Aurangabad is the capital metro city of Maharashtra State, India. This is the fastest increasing city in the world which is surrounded by hills on all directions as well as lots of historical monuments[14].Most of the samples are collected from Aurangabad city . . Both cities have three distinct season and plenty of sunshine. The climate of Aurangabad region is semiarid The annual mean temperature of Aurangabad city range from 17 to $33{ }^{\circ} \mathrm{C}$, average annual rainfall is $710 \mathrm{~mm}$. Soil type is mostly black and brown soil .

\subsection{Soil samples collections}

For this experiment we created soil database, which consists of 30 samples of soil from farms. The samples include top soil (0-20 cm depth from land surface). Soil samples were collected from the Aurangabad and Jalna city of India during January to march 2016 between 10: $00 \mathrm{am}$ to 6: $00 \mathrm{pm}$ on a sunny day. University are ,Himayat bag, Himayat nagar, Zalta, Paithan road, Mharola these are the locations of Aurangabad city. Sashta-pimpalgaon, Aapegaon, Ambad these are the locations of Jalna city . It has been collected from different cropping systems, including arable. A global position system (GPS) was used to determine the coordinates of the sampling point.

\subsection{Database creation}

Database is developed by FieldSpec 4 Spectroradiometer using RS3 software. Soil database contain 30 soil samples. The reflectance spectra of each sample is calculated using Fieldspec 4.We took 10 successive scans of each sample. . For this soil samples were scanned using high intensity source instrument with a spectral range of 350-2500nm[15] . We have 30 soil samples and each samples was scanned 10 times, so we got 300 soil samples of different area. The setup of instrument and soil sample is done as follows. Distance between optical head and soil sample was $30 \mathrm{~cm}$ with a lamp mounted on distance $90 \mathrm{~cm}$ form sample. Room temperature was about $18{ }^{\circ} \mathrm{C}$. All spectral data were collected by RS3 software and post processing of data is done by view spec pro software. We got 300 soil spectra's for 30 samples. Then by taking mean of each 10 samples collected by same region we have created the database of 30 spectra's. These spectral signatures were in ASD format.

\subsection{Data Preprocessing}

It is a hyper spectral data which is non imaging data and able to predict the soil properties. ViewSpec Pro software was used for pretreatment and each spectral signature transformed into ASCII format by using the ViewSpecPro software[16].

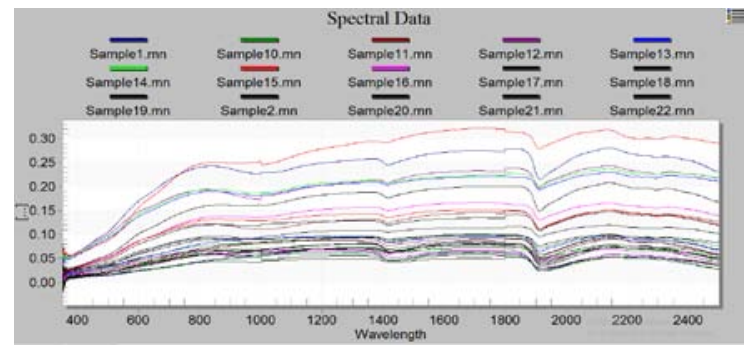

Fig 1: Statistics mean spectral signature of all 30 samples

The wavelength bands 403nm, 470nm, 687nm, 846nm, $1702 \mathrm{~nm}, 1870 \mathrm{~nm}, 2052 \mathrm{~nm}$ are highly reflective to the soil nitrogen content .Mean reflectance value of soil is calculated for statistical analysis which is shown in fig1. Smoothing operation is done by using Savitzky Golay method using Matlab for post processing [17].The preprocessing is done using view-spec pro. The table 1 shows the average amount and \%amount of nitrogen for each soil sample.

Table 1: Average and \% of Nitrogen content of all 30 samples

\begin{tabular}{|c|c|c|}
\hline Sample no & $\begin{array}{l}\text { Nitrogen } \\
\text { content }\end{array}$ & $\%$ content \\
\hline 1 & 0.154 & 15.4 \\
\hline 2 & 0.0938 & 9.38 \\
\hline 3 & 0.0876 & 8.76 \\
\hline 4 & 0.1127 & 11.27 \\
\hline 5 & 0.13 & 13.0 \\
\hline 6 & 0.1327 & 13.27 \\
\hline 7 & 0.1181 & 11.81 \\
\hline 8 & 0.0962 & 9.62 \\
\hline 9 & 0.0597 & 5.97 \\
\hline 10 & 0.0439 & 4.39 \\
\hline 11 & 0.0415 & 4.15 \\
\hline 12 & 0.0413 & 4.13 \\
\hline 13 & 0.0417 & 4.17 \\
\hline 14 & 0.0417 & 4.17 \\
\hline 15 & 0.0466 & 4.66 \\
\hline 16 & 0.0433 & 4.33 \\
\hline 17 & 0.0335 & 3.35 \\
\hline 18 & 0.0315 & 3.15 \\
\hline 19 & 0.0376 & 3.76 \\
\hline 20 & 0.0452 & 4.52 \\
\hline 21 & 0.0435 & 4.35 \\
\hline 22 & 0.0551 & 5.51 \\
\hline 23 & 0.0507 & 5.07 \\
\hline 24 & 0.051 & 5.1 \\
\hline 25 & 0.0502 & 5.02 \\
\hline 26 & 0.0492 & 4.92 \\
\hline 27 & 0.0676 & 6.76 \\
\hline 28 & 0.0536 & 5.36 \\
\hline
\end{tabular}




\begin{tabular}{|l|l|l|}
\hline 29 & 0.0515 & 5.15 \\
\hline 30 & 0.0271 & 2.71 \\
\hline
\end{tabular}

\section{MODELING :PARTIAL LEAST SQUARE REGRESSION}

PLSR is a statistical method which contains relation to principle component. Predictors are reduces to the smaller set of uncorrelated components using PLSR .Instead of original data PLSR perform least square regression on these uncorrelated components[18]. It is best because it reduces the noise and detects the unknown samples which are not represented by calibration model. Build a linear model about $\mathrm{X}$ and $\mathrm{Y}$ is a basic aim of PLS Regression.

Formula for PLSR model :

$\mathrm{Y}=\mathrm{UQ}+\mathrm{F}$

$\mathrm{X}=\mathrm{TP}+\mathrm{E}$

Where $\mathrm{X}$ is mean-centered matrix of predicted variables and $\mathrm{Y}$ is mean-centered matrix of response variable. $\mathrm{U}$ and $\mathrm{T}$ are score matrices where as $\mathrm{Q}$ and $\mathrm{P}$ are loading matrices; $\mathrm{F}$ and $\mathrm{E}$ are error matrices. Considering the correlation between the feature vector, we can establish the regression model by decomposing $\mathrm{X}$ and $\mathrm{Y}$ :

$\mathrm{U}=\mathrm{TB}+\mathrm{Ed}$

Where $\mathrm{B}$ is regression coefficient matrix and $\mathrm{Ed}$ is random error matrix.

So, to predict the $\mathrm{TN} y$ when special vector $\mathrm{x}$ is known $\mathrm{y}=\mathrm{x}(\mathrm{UY})^{\prime} \mathrm{BQ}$

In this study we are implemented PLSR algorithm using Matlab 2010.

\section{RESULT AND DISCUSSION}

5.1 3D plot : 3D plot (fig : 2) display the graph of all 30 samples with corresponds to the values on the particular wavelength. In this $\mathrm{x}$-axis shows the wavelength which are sensitive to nitrogen, $y$-axis shows the sample numbers.

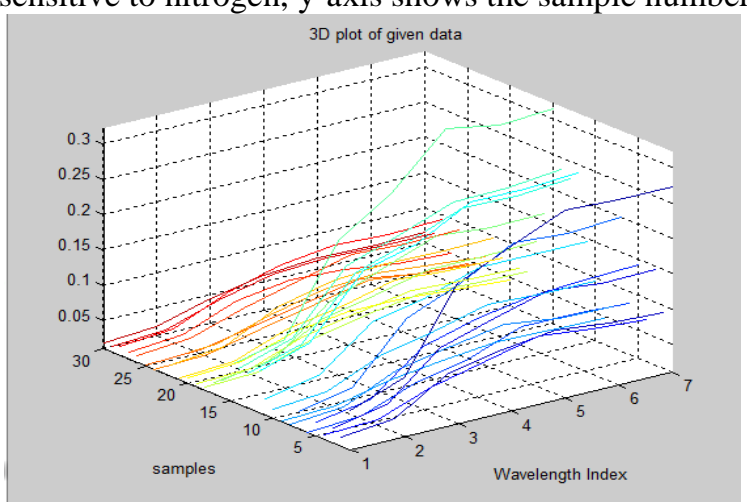

Fig 2 : 3D plot of Given Data

5.2 Percent variance explained in $\mathbf{Y}$ and $\mathrm{X}$ : Using these plots (fig $3 \& 4$ ) we can make choice of simpler model with fewer components. In this plot we choose number of component to plot the percent of variance explained in the response variable as a function of number of component.

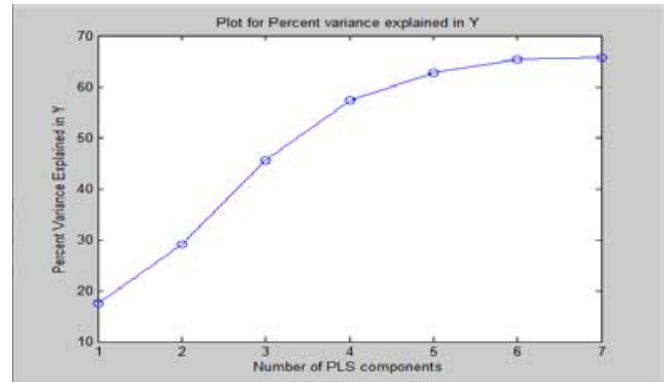

Fig 3: Percent Variance Explained in $Y$

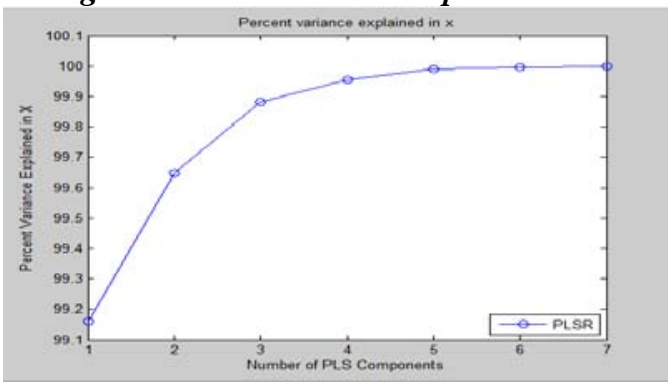

Fig 4: Percent Variance Explained in $X$

5.3 Fitted vs. Observed Response: Using this plot(fig 5) we get the idea of total fitted samples with respect to observed response of sample. $\mathrm{X}$ axis contain observed response of samples where as $\mathrm{Y}$ axis contain fitted response of the sample.

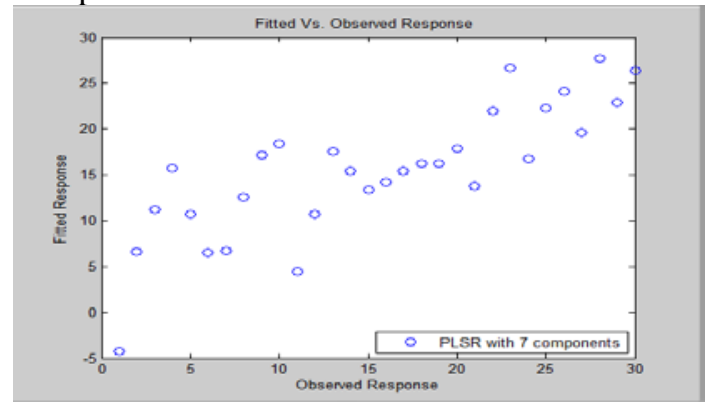

Fig 5: Fitted Vs Observed Response

5.4 Scores Plot of $\mathbf{X}$ and $\mathbf{Y}$ : Using these Scores plot(fig 6 \& 7) we get the information about the sample patterns. Scores plot also gives the information about the differences and similarities among the sample. It also helps to determine which variable is responsible for difference between sample.

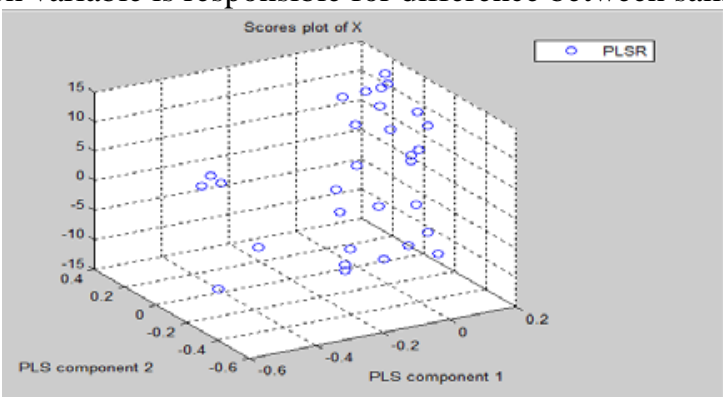

Fig 6: Scores plot of $X$ 


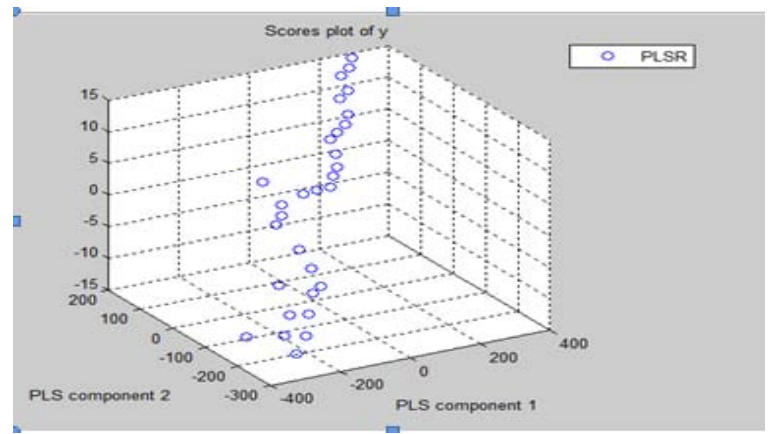

Fig 7: Scores plot of $Y$

5.5 Predicted vs Reference Plot : In predicted Vs Reference plot (fig:8) we are using selected predicted X,Y values from the model which is plotted against the reference $\mathrm{X}, \mathrm{Y}$ value. This plot is used to check the quality of regression model[20].

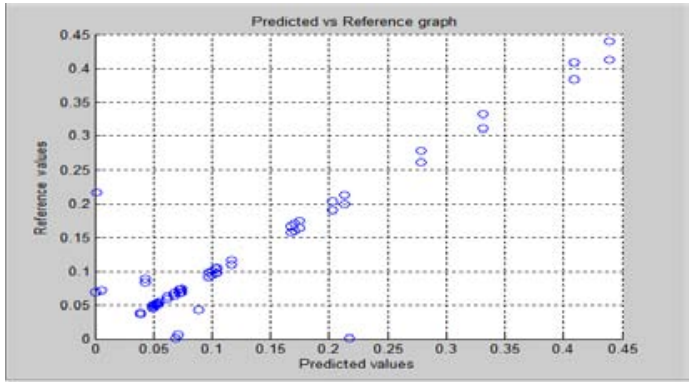

Fig 8: Predicted Vs Reference Values

\section{CONCLUSION}

Nitrogen is the essential macronutrient of the soil which is essential for the crop production. So the framer must have the knowledge about the soil nitrogen content to improve the crop production. In this paper we are using ASD fieldspec 4 to get the soil spectra of the collected samples. From those spectra we got $403 \mathrm{~nm}, 470 \mathrm{~nm}, 687 \mathrm{~nm}, 846 \mathrm{~nm}, 1702 \mathrm{~nm}$ ,1870nm, 2052nm these wavelength which have high reflectance to nitrogen content. We got RMSE $=0.0039$ for calibration and RMSE $=0.0043$ for validation. $\mathrm{R}^{2}=0.9320$ for calibration and $\mathrm{R}^{2}=0.9259$ for validation. The total nitrogen content calculated in the selected study area is listed in table 1. From the fig. 4 Line plot we get the idea of soil total nitrogen content in all samples using this plot we can also check the sustainability of the soil. By using score, loadings and variance plots we get information about differences and similarities between soil samples. In scores plot, the samples which are away from each other are different from each other. In score plot the samples are present in positive loading as well as negative loading. Positive loading have higher than average value and negative loadings shows lower than average value. Variance graph shows how the data can be represented in PLSR model.

\section{ACKNOWLEDGEMENT}

This work is supported by Department of Science and Technology under the Funds for Infrastructure under Science and Technology (DST-FIST) with sanction no. SR/FST/ETI-340/2013 to Department of Computer Science and Information Technology, Dr. Babasaheb Ambedkar
Marathwada University, Aurangabad, Maharashtra, India. The authors would like to thank Department and University Authorities for providing the infrastructure and necessary support for carrying out the research.

\section{REFERENCES}

1) Haney, Richard L., W. H. Brinton, and Eric Evans. "Estimating soil carbon, nitrogen, and phosphorus mineralization from short-term carbon dioxide respiration." Communications in Soil Science and Plant Analysis 39.17-18 (2008): 2706-2720.

2) Padmanabhi Ashwini Dilip, and Ratnadeep R. Deshmukh. "Hyperspectral Analysis of Soil Total Nitrogen using PLSR Method: A Review." International Journal of Theoretical and Applied Mechanics 12.2 (2017): 357-364.

3) Wei, $\mathrm{Yu}$, et al. "Monitoring Soil Nitrate Nitrogen Based on Hyperspectral Data in the Apple Orchards." Sciences 8 (2017): 21-32.

4) Shi, Tiezhu, et al. "Comparison of multivariate methods for estimating soil total nitrogen with visible/near-infrared spectroscopy." Plant and soil 366.1-2 (2013): 363-375.

5) Feyziyev, Fikrat, et al. "Using visible-near infrared spectroscopy to predict soil properties of mugan plain, Azerbaijan." Open Journal of Soil Science 6.03 (2016): 52.

6) Lin, Lixin, et al. "Hyperspectral Analysis of Soil Total Nitrogen in Subsided Land Using the Local Correlation Maximization-Complementary Superiority (LCMCS) Method." Sensors 15.8 (2015): 17990-18011.

7) Bansod, Sneha J., and Shubhadha Thakre. "Near Infrared Spectroscopy based Soil Nitrogen measurement-A Review." International Journal of Current Engineering and Technology 4.1 (2014): 268-272.

8) Shu, X. M., et al. "Estimating soil total nitrogen contents from visible/near-infrared reflectance based on successive projections algorithm." IOP Conference Series: Earth and Environmental Science. Vol. 17. No. 1. IOP Publishing, (2014).

9) Gore, Ramdas D., Reena H. Chaudhari, and Bharti W. Gawali. "Creation of Soil Spectral Library for Marathwada Region." International Journal of Advanced Remote Sensing and GIS (2016): pp-1787.

10) Liu, Xiang, et al. "Assessment and mapping of soil nitrogen using Visible-Near-Infrared (Vis-NIR) spectra." ISPDI 2013Fifth International Symposium on Photoelectronic Detection and Imaging. International Society for Optics and Photonics, (2013).

11) Kulkarni, Snehal N., and Dr Ratnadeep R. Deshmukh. "Monitoring Carbon, Nitrogen, Phosphor and Water Contents of Agricultural Soil by Reflectance Spectroscopy using ASD Fieldspec." IJSC. Published (2016).

12) Peng, Xiaoting, et al. "Estimating soil organic carbon using VIS/NIR spectroscopy with SVMR and SPA methods." Remote Sensing 6.4 (2014): 2699-2717.

13) Kharat, Rahul B., and Dr Ratnadeep R. Deshmukh. "Analysis of Effective Leaf Nitrogen Concentrations in Tomato Plant using Vegetation Indices." International Journal of Engineering Science 2397 (2016).

14) https://en.wikipedia.org/wiki/Aurangabad,_Maharashtra Accessed on: 5 Aug 2016.

15) https://www.asdi.com/products-and-services/fieldspecspectroradiometers Accessed on : 15 Nov 2016

16) Gore Ramdas D., Sunil S. Nimbhore, and Bharti W. Gawali. "Understanding Soil Spectral Signature Though RS and GIS Techniques." (2015).

17) $\mathrm{Du}$, Changwen, and Jianmin Zhou. "Evaluation of soil fertility using infrared spectroscopy: a review." Environmental Chemistry Letters 7.2 (2009): 97113. 
18) Shi, Z., et al. "Prediction of soil organic matter using a spatially constrained local partial least squares regression and the Chinese vis-NIR spectral library." European Journal of Soil Science 66.4 (2015): 679-687.

19) $\mathrm{Li}$, Shuo, et al. "Potential of VIS-NIR-SWIR Spectroscopy from the Chinese Soil Spectral Library for Assessment of
Nitrogen Fertilization Rates in the Paddy-Rice Region, China." Remote Sensing 7.6 (2015): 7029-7043.

20) http://www.camo.com/downloads/U9.6\%20pdf\%20manual/ The\%20Unscrambler\%20Methods.pdf Accessed on : March 2017 